\title{
Coastal Accessibility and Availability for Physical Activity: A Cross-Sectional Assessment in New Zealand Adults
}

\author{
Nick Garrett ${ }^{1}$, Melody Smith ${ }^{2}$, Philip J. Schluter ${ }^{3,4}$, Barbara Bollard-Breen ${ }^{5}$ \\ ${ }^{1}$ Department of Epidemiology and Biostatistics, Auckland University of Technology, Auckland, New Zealand \\ ${ }^{2}$ School of Nursing, The University of Auckland, Auckland, New Zealand \\ ${ }^{3}$ School of Health Sciences, University of Canterbury-Te Whare Wānanga o Waitaha, Christchurch, New Zealand \\ ${ }^{4}$ School of Nursing, Midwifery and Social Work, The University of Queensland, Brisbane, Australia \\ ${ }^{5}$ School of Applied Sciences, Auckland University of Technology, Auckland, New Zealand \\ Email: ngarrett@aut.ac.nz
}

How to cite this paper: Garrett, N., Smith, M., Schluter, P.J. and Bollard-Breen, B. (2016) Coastal Accessibility and Availability for Physical Activity: A Cross-Sectional Assessment in New Zealand Adults. Open Journal of Preventive Medicine, 6, 273-286. http://dx.doi.org/10.4236/ojpm.2016.612025

Received: November 21, 2016

Accepted: December 4, 2016

Published: December 7, 2016

Copyright $\odot 2016$ by authors and Scientific Research Publishing Inc. This work is licensed under the Creative Commons Attribution International License (CC BY 4.0).

http://creativecommons.org/licenses/by/4.0/ (c) (i) Open Access

\begin{abstract}
Background: This study aimed to examine cross-sectional relationships between objective measures of the built environment (neighborhood walkability and access to and availability of public open spaces including the coast) with self-reported physical activity in adults residing in Auckland, New Zealand. Methods: A telephone survey captured self-reported physical activity and socio-demographic information from adult residents from randomly selected households. Robust approaches were employed to deriving and "ground-truthing" objective built environment measures around individual addresses. Multivariable binary logistic regression models were used to examine the associations between environmental factors and being classified as accumulating sufficient physical activity or otherwise. Results: A total of 1986 participants agreed to participate. Compared with those with no coastal access points within an $800 \mathrm{~m}$ street network buffer of their residence, those with $1-2$ access points were 1.45 times more likely to be classified as sufficiently active (95\% CI 1.08, $1.94, \mathrm{p}=0.05)$. Compared with individuals with no coastal settings within their neighborhood buffer, those with at least two coastal settings in their neighborhood were significantly more likely to be sufficiently active $(p=0.03)$. Conclusion: Access to, and availability of, coastal places were important associates of accumulating sufficient activity for health in this population.
\end{abstract}

\section{Keywords}

Built Environment, Environment, Health Behaviour 


\section{Introduction}

Neighborhood design is increasingly recognized as a means to encourage healthpromoting levels of physical activity in adults, primarily through transport-related physical activity (i.e., walking or cycling for transport) and recreational physical activity (e.g., playing sports at local fields). Associations between physical activity and measures of "walkablity" (e.g., street connectivity, residential dwelling density) have been demonstrated [1]. The presence of resources and settings (e.g., open spaces, facilities) for residents to participate in physical activity may also encourage activity [2] [3].

One area that has received little attention to date is that of coastal access. Research that has been conducted has shown positive relationships with general and mental health [4] [5] with physical activity hypothesized to contribute to these relationships. Indeed, coastal proximity has consistently been associated with physical activity and meeting recommended levels of physical activity for health [6] [7] [8]. To date, measures of coastal access have been relatively broad, and limited to Euclidean (linear or straight line distances) distances to the coast, or residing within a postcode that includes coastal land, which may not accurately represent areas that are accessible from the individual's residence [9]. The use of network buffers (using street and/or pathway networks), to create an area that encompasses everything that is within a set distance along that network from the residential address improves on earlier approaches, providing more representative indications of the area that an individual can readily access from their residential address.

To some extent, this field can also be hindered by variability in GIS database quality, which can have a significant impact on the results of any GIS analysis [10]. Accordingly it is important to determine the providence, accuracy and currency of GIS data, however there is a dearth of research that reports rigorous checking and cleaning of these data. New Zealand has been recognized as having developed some of the best GIS databases internationally; in particular, North Shore City Council (NSC) received an international award for their on-line GIS web-pages in 2004 from the United States Environmental Systems Research Institute.

The aim of this study was to build on earlier research by: 1) undertaking rigorous cleaning and checking of GIS databases, and 2) examining associations between physical activity and a range of objectively derived measures using a street network plus access-way neighborhood buffer, and including coastal access and coastal availability as key factors of interest.

\section{Methods}

\subsection{Protocol}

This was a cross-sectional study of a representative sample of adult residents of NSC, Auckland, New Zealand. A computer-aided telephone (CATI) survey was conducted in 2005 to capture self-reported physical activity behaviors and socio-demographic information. Using residential addresses the survey data was linked to a NSC spatial database, containing information about street networks, local neighborhood features, and 
recreational facilities. Ethical approval to conduct the research was provided by the Host Institution's ethics committee. All participants provided informed consent prior to participating.

The CATI was conducted with an age and sex stratified sample of NSC residents aged 16 years and over. Inclusion criteria were: residents of NSC, aged 16 years and

over, fluent in English, and contactable by residential telephone. Randomly selected households from an electronic version of the local telephone directory were telephoned a maximum of five times until contact was made. Quotas were set up for age group (16 - 29, $30-44,45-59,60+$ years) and sex strata, based on data from the 2001 census for NSC. An English-speaking person with the next birthday from the household and whose inclusion did not exceed the quota for their age and sex stratum was invited to participate in the survey. A sample size of 2000 completed surveys was calculated to allow for adequate population estimates to be made within a $\pm 3 \%$ confidence for estimating even proportions by sex, and selected age, ethnicity, and socio-demographic variables.

\subsection{Measures}

\section{Survey data}

Physical activity and demographic information were extracted for the purposes of this examination as follows:

Residential address: Participants were asked for their full residential addresses, or if unwilling to give the full address, to provide the nearest major street intersection. Participants with a full residential address were geo-coded to the given address, utilizing a cadastral database of addresses for NSC provided by NSC Council. In a few cases where the exact street number provided did not exist on the database, they were allocated to the next street number that existed. Participants who gave no street number were randomly allocated without replacement to an address on the recorded street and suburb. Those who gave a cross street were randomly allocated to an address within a half block of the major intersection.

Demographic information: sex (male, female), ethnicity group (classified using priority classifications as follows: Māori, Pacific, Asian, European, other [11]), age group, presence of any chronic health conditions (yes/no), household income group (reported in bands of NZ\$20,000, up to $>\$ 140,000$ per annum), highest educational qualification (no qualification, secondary qualification, tertiary qualification, university degree, or currently studying), marital status (single, married/living with partner, separated/divorced, widowed), and perceived access to motor vehicle (none, limited, frequent, unlimited) were self-reported.

Physical activity was self-reported using the New Zealand Physical Activity Questionnaire [12]. Physical activity was classified into a binary outcome: 1) sufficiently active (i.e., meeting recommended levels of physical activity), or 2) insufficiently active (did not meet the recommended levels of physical activity). To be classified as sufficiently active, participants need to accumulate either: three or more 20-minute sessions per week of vigorous activity marked by elevated respiration and heart rate (e.g., jog- 
ging); or five or more 30-minute sessions per week of moderate aerobic activity (e.g., brisk walking) [13].

\section{GIS source data}

NSC and Auckland Regional Council provided GIS information on the local environment, which was incorporated in the GIS database, including street network, access-ways, open spaces, property boundaries, and building zones. Additional data were included from the national census database for 2006 (to align most closely with the survey dates) on the New Zealand deprivation index, and population and household density (available at the meshblock level, the smallest census geographical unit; equating to, on average about 100 residents).

\section{Calculation of individual neighborhood boundaries}

An $800 \mathrm{~m}$ street network plus access-way (paved walkways between streets) buffer was calculated around individual addresses that incorporated all points that could be reached by both the street and access-ways within the specified distance (Figure 1). Where the local neighborhood encompassed the coast or major waterways, the area was trimmed to include only the relevant land area.

\section{Walkability measures}

This research examined separate elements of the walkability index [14], as outlined below.

Street connectivity: density of intersections of three or more streets per square kilometer.

Residential density: number of households per residential zoned area $\left(\mathrm{km}^{2}\right)$.

Land-use mix was calculated using an entropy index, which utilizes the proportion of land area in each land-use category to measure the homogeneity or heterogeneity of land-use.

Retail floor area: There were issues with the calculation of retail floor area with the available data for NSC. In particular, NSC did not have a land-use classification for retail sites only. Therefore, the available estimates of retail floor area were not considered sufficiently reliable for inclusion in this research.

\section{Destinations}

Coastal Access: Not all beach access points were readily identifiable from only the street and access-way network data. Street networks and high-resolution aerial maps of the region were manually reviewed, in order to identify all the points where the coast was publicly accessible from the street network.

Open Spaces were classified as: community recreation, destination, natural environment, coastal, neighborhood, utility, and civic. Additional open spaces that were operated over the Auckland region or privately owned but open to the public were not in the database, but were manually added and classified as appropriate into the above categories. The open space map layer was overlaid with the recreation district plan map layer to confirm concordance between the two layers. A number of data quality issues were resolved including missing data and misclassification of setting use. Utility open spaces (drainage, road verges, etc.) and open spaces less than 100 square meters in size 


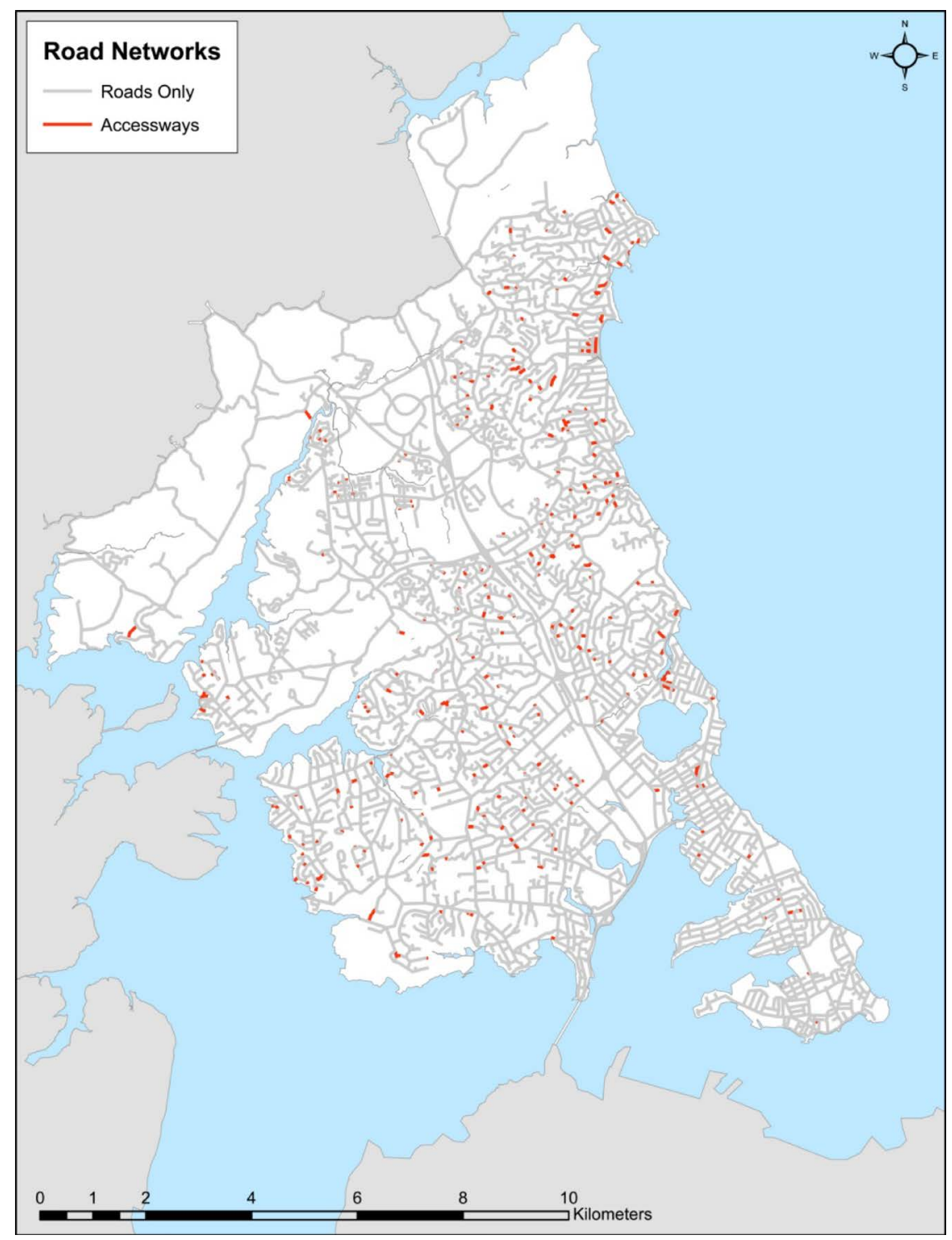

Figure 1. Map of north shore city street and access-way networks.

(and not adjoining other open spaces) were excluded.

Facilities: Initially, facilities in NSC were identified through databases managed by NSC Council, the local community boards within NSC, and Harbour Sport (the regional public organization that facilitates and coordinates local sports activities). Additional facilities and information from the local telephone directory of businesses and website searches were incorporated. The initial database was then validated by phone contacts with all identified facilities. All sites were then linked to the NSC cadastral database (survey of legal boundaries and property areas and dimensions). This final database was then incorporated into an on-line database (maintained by NSC), for residents to locate any local facilities. After a year of the database being on-line, five new premises were added to the database and two were identified as no longer operating. A copy of the final database was extracted and used as a comprehensive list of facilities in NSC for this 
research. As a quality check, the database was compared with GIS databases sourced from NSC on open spaces, sports fields, courts and greens, and data collected as part of an environmental audit of the city. Several errors in the database were identified and corrected (e.g., incorrect classifications, missing destinations).

\section{Data Analysis}

Two measures were developed for examining associations with physical activity facilities and destinations (coastal access, open spaces): 1) shortest distance from the residential address to the closest facility was calculated using Network Analysis within ArcGIS software version 10 (www.esri.com), and 2) the number of facilities within an $800 \mathrm{~m}$ buffer (using the street network plus access-ways) of the residential address was calculated using spatial analysis tools within ArcGIS. Descriptive maps were generated and presented in the GCS_NZGD_2000 geographic co-ordinate system and New Zealand Transverse Mercator projected coordinate system.

Multivariable binary logistic regression models were used to examine the associations between environmental factors and being classified as accumulating sufficient physical activity or otherwise. Sampling weights for the statistical analysis were calculated using the sample selection probabilities and post-stratification weighting to adjust for differential non-response. All models were adjusted for sex, ethnicity group, age group, presence of any chronic health conditions, household income group, education, marital status, access to motor vehicle, and sampling weights. All environmental measures were categorized into quartiles. Analyses were conducted using SAS version 9.1 (www.sas.com), and a significance level of $\alpha=5 \%$ was used for all statistical tests. Analyses and presentation of this paper was informed by the Strengthening the Reporting of Observational Studies in Epidemiology (STROBE) guidelines [15].

\section{Results}

Of the 9197 phone numbers contacted, a total of 6028 were residential telephone numbers within NSC boundaries. When the residential suburbs of the 2000 participants were examined, 1986 were sited within the boundaries of North Shore, equating to a final response rate of 33\% (1986/6028). In order to preserve their anonymity, suburb information only was available for residents who declined to participate. This information was used to calculate response rates for each suburb to identify if there was any geographic bias in the response rates. Overall, the response rates were consistent across suburbs. Of the 1986 addresses gathered, 1607 (81\%) were able to be exactly geo-coded due to reporting of complete addresses, $4 \%$ to the next available address because the reported street number did not match any address in NSC cadastral database, another $4 \%$ to within half a block of the nearest cross street. Overall, $11 \%$ were randomized without replacement within the reported street and suburb.

Participant characteristics are provided in Table 1. The distribution of participant demographics was similar to that of the NSC census population in 2006. Due to low numbers of participants identifying as Pacific or Māori ethnicity, and because the 
Table 1. Participant demographic information $(n=1983)$.

\begin{tabular}{|c|c|c|}
\hline Variable & $\mathbf{N}$ & $(\%)$ \\
\hline \multicolumn{3}{|l|}{ Sex } \\
\hline Male & 877 & $(44.2)$ \\
\hline Female & 1106 & $(55.8)$ \\
\hline \multicolumn{3}{|l|}{ Age group } \\
\hline $16-29$ & 405 & $(20.4)$ \\
\hline $30-39$ & 401 & $(20.2)$ \\
\hline $40-49$ & 448 & $(22.6)$ \\
\hline $50-59$ & 331 & $(16.7)$ \\
\hline $60+$ & 398 & $(20.1)$ \\
\hline \multicolumn{3}{|l|}{ Ethnicity } \\
\hline Māori/Pacific & 106 & $(5.3)$ \\
\hline European & 1647 & $(83.1)$ \\
\hline Asian & 154 & $(7.8)$ \\
\hline Other & 63 & $(3.2)$ \\
\hline Not reported & 13 & $(0.7)$ \\
\hline \multicolumn{3}{|l|}{ Marital status } \\
\hline Single & 451 & $(22.7)$ \\
\hline Married/living with partner & 1229 & $(62.0)$ \\
\hline Separated/divorced & 186 & $(9.4)$ \\
\hline Widow/er & 109 & $(5.5)$ \\
\hline Not reported & 8 & $(0.4)$ \\
\hline \multicolumn{3}{|l|}{ Any chronic conditions } \\
\hline No & 1530 & $(77.2)$ \\
\hline Yes & 453 & $(22.8)$ \\
\hline \multicolumn{3}{|l|}{ Household income (NZ\$) } \\
\hline $0-20,000$ & 183 & $(9.2)$ \\
\hline $20,001-40,000$ & 263 & $(13.3)$ \\
\hline $40,001-60,000$ & 285 & $(14.4)$ \\
\hline $60,001-80,000$ & 295 & $(14.9)$ \\
\hline $80,001-100,000$ & 232 & $(11.7)$ \\
\hline $100,001-140,000$ & 249 & $(12.6)$ \\
\hline$>140,000$ & 179 & $(9.0)$ \\
\hline Not reported & 297 & $(15.0)$ \\
\hline \multicolumn{3}{|l|}{ Education } \\
\hline No qualification & 199 & $(10.0)$ \\
\hline Secondary school qualification & 487 & $(24.6)$ \\
\hline Tertiary (university, tech) qualification & 540 & $(27.2)$ \\
\hline University degree & 681 & $(34.3)$ \\
\hline Currently studying & 67 & $(3.4)$ \\
\hline Not reported & 9 & $(0.5)$ \\
\hline \multicolumn{3}{|l|}{ Motor vehicle access } \\
\hline Unrestricted & 1607 & $(81.0)$ \\
\hline Frequent & 228 & $(11.5)$ \\
\hline Limited & 63 & $(3.2)$ \\
\hline None & 85 & $(4.3)$ \\
\hline
\end{tabular}


physical activity profiles of these two groups were similar (data not reported), these ethnic groups were combined for the purpose of adjusting for confounding in the modeling.

Results from the multivariable binary logistic regression analyses are presented in Table 2 and Table 3. No significant associations were observed between being classified as sufficiently active and any of the walkability variables or distance or number of facilities within $800 \mathrm{~m}$ of the residential address. Coastal access and coastal availability (having two or more coastal open spaces within the neighborhood buffer) were the only factors associated with being sufficiently active.

\section{Discussion}

Coastal accessibility and availability (number of access points and number of coastal open spaces within the neighborhood buffer, respectively) were the only associates of being classified as sufficiently physically active for health in the current study. This is consistent with previous research from Australia and the United Kingdom [6] [7] [8]. This study builds on earlier research by using a more precise measure of coastal access (i.e., distance via street network to access points rather than residing in a postcode that included coastal land, or Euclidean distances to the coast). Additionally, access was considered in terms of proximity to destinations within the "walkable" neighborhood.

It is possible that the high prevalence of coastal access and availability in the current study region overrode the impact of other open spaces on residents' activity levels. Inconsistent findings have been reported regarding accessibility to other open spaces and physical activity [16] [17]. Previous research in New Zealand by Pearce et al. [18] showed no associations between physical activity and objective accessibility measures for beaches, parks, or leisure facilities. However, this study used national databases of parks and beaches and measured the street network distances to the destinations, calculated from the population-weighted centroid of the smallest census unit of meshblock, which equates to approximately 100 residences. In contrast, the current study utilized local council open-space data and an audit of NSC to identify all open spaces and street network distances from residential addresses to destinations.

No significant relationships were observed for any of the walkability measures. Inconsistent results have been observed in previous research, with positive relationships observed in New Zealand and internationally, particularly for street connectivity and residential density [1] [19] [20], while other international research has shown small or no associations between these measures and total physical activity [21] [22] [23].

In part the current study findings could also be due to a lack of variability in land-use mix and residential density across NSC. The city was initially predominantly a rural region, with small coastal settlements that were primarily vacation or daytrip destinations, linked to central Auckland by ferries. The construction of the Auckland Harbour Bridge in 1959 opened up the region for development and resulted in parts of NSC becoming primarily a dormitory town for people working in the Auckland CBD or further south. NSC has since developed into a more self-contained city, but still has the in- 
Table 2. Associations between meeting recommended levels of physical activity and urban design characteristics, using an $800 \mathrm{~m}$ street network plus access-way buffer.

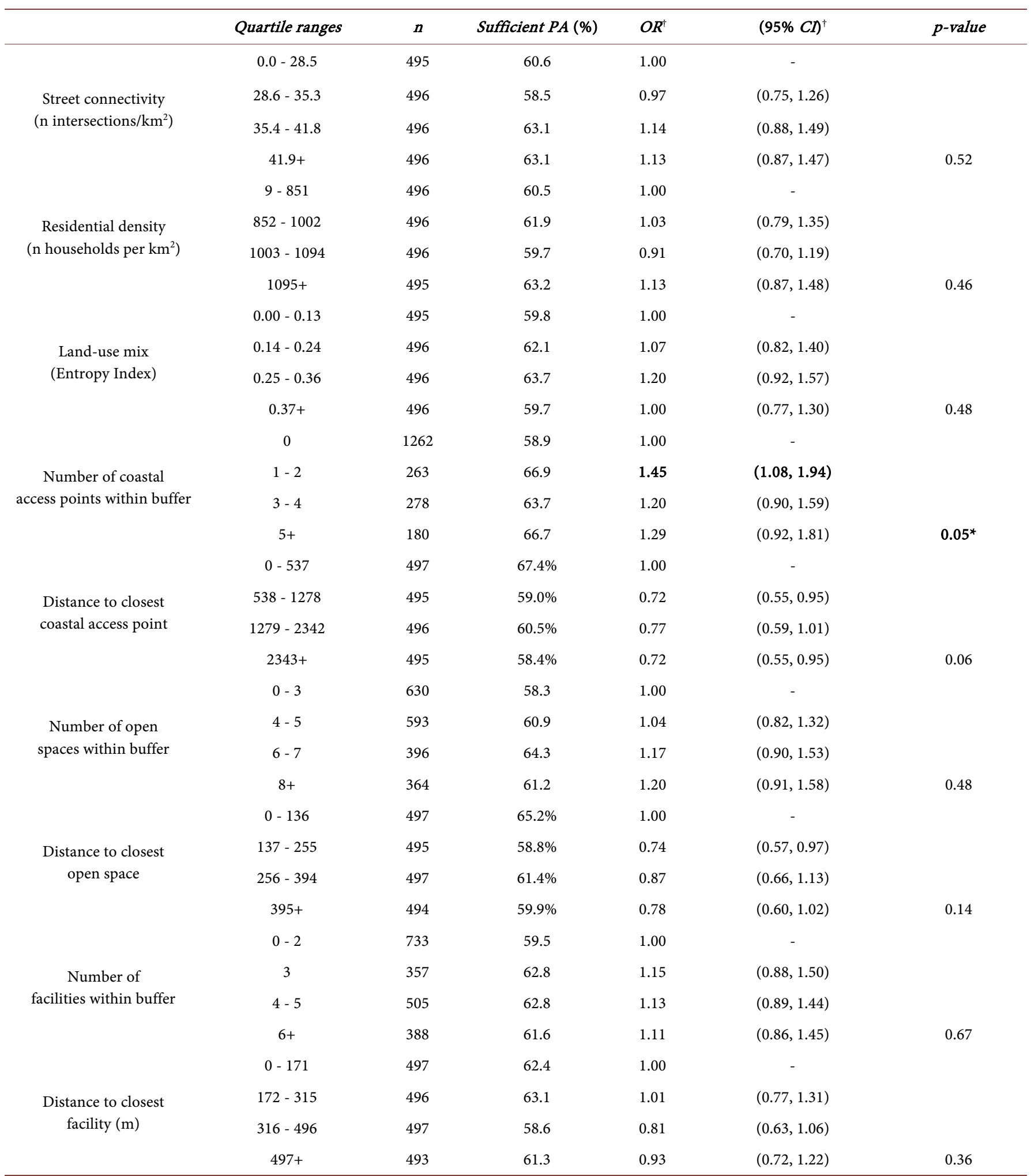

Notes: OR, odds ratio; PA, physical activity; ${ }^{\star}$ Significant at $\mathrm{p}<0.05 ;{ }^{\dagger}$ Adjusted for age, sex, ethnicity, household income, education, any chronic conditions, marital status, access to motor vehicle, and sample weights. 
Table 3. Associations between sufficient physical activity and (a) number of open spaces in the 800 m street network plus access way buffer and (b) distance from residential address to closest open space, by type of open space.

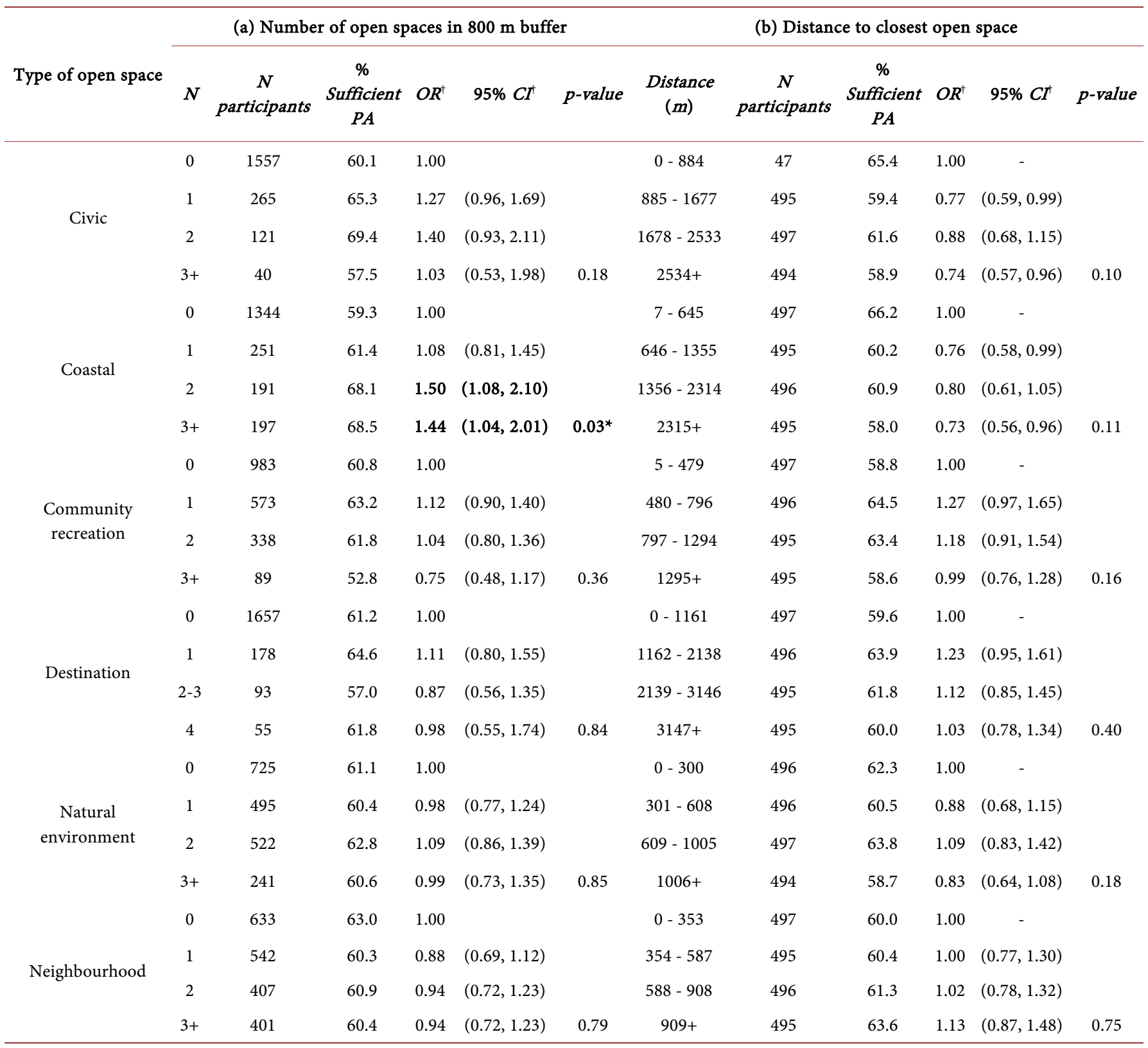

${ }^{*}$ Significant at $\mathrm{p}<0.05 ;{ }^{\dagger}$ Adjusted for age, sex, ethnicity, household income, education, any chronic conditions, marital status, access to motor vehicle, and sample weight.

frastructure from its earlier developments [24]. Consequently, there are only a few small areas of very high-density housing, and generally good separation of commercial, rural, and residential areas. Conversely, the historical development of NSC has resulted in considerable variability in connectivity with older settlements' street networks being developed in a highly connected grid-like pattern, whereas the newer developments from the 1960s onwards developed less connected, cul-de-sac designs that were popular at the time. 


\section{Strengths and Limitations}

Key strengths of this research are the large, locally representative sample size, the use of a street network plus access-way neighborhood buffer, and the overall quality of the NSC GIS databases for street networks, open spaces, and the development of a comprehensive physical activity facility database. The quality of the GIS databases and developments of GIS software have enabled the calculation of reliable measures of the local environment.

The use of network buffers for connectivity does raise some issues in that as the network connectivity actually drives the size of the network buffer, the connectivity measures are potentially over-inflated. The calculation of the entropy index measure of land-use mix in this research was also limited by the categories of land-use that were available. As demonstrated in recent research [25], the combination of land-use mix categories can have a major impact on associations.

As this was a cross-sectional study, causality cannot be inferred. Although we controlled for socio-demographic factors in modeling relationships between environmental factors and physical activity, we did not specifically assess individual or social factors and their influence on this relationship. In their examination of 1803 Australian adults, Giles-Corti et al. [26] found that while use of the beach was significantly related to spatial access, sufficient physical activity was not associated with spatial access to natural facilities (including the beach). Instead, the associations were greatest for individual/ cognitive factors as compared with social or physical environment factors. We did not consider the possible mediating effect of visitation on the relationship between access and physical activity. A population study of adults in the United Kingdom showed that after accounting for visitation, the gradient observed between coastal proximity and physical activity disappeared [8].

Self-reported physical activity behaviours are notoriously subject to self-report bias, including issues around recall, comprehension, and social desirability bias [27] [28]. Evidence for validity and utility of the New Zealand Physical Activity Questionnaire has ben demonstrated [12]. However, it is worth noting that in New Zealand adults, comparisons between the International Physical Activity Questionnaire or New Zealand Physical Activity Questionnaire and objective measures of physical activity have shown low levels of agreement at the individual level, particularly for higher intensity activities [29] [30]. Accordingly, data were examined at the group level, and focused on accumulation of sufficient levels of physical activity for health, rather than a more discrete measure of physical activity. Results cannot be directly compared with studies that have employed objective measures of physical activity.

Neighborhood self-selection was not assessed in the current study and may have impacted findings. Analyses were limited to examining associations with built environment features in isolation; future research may benefit from simultaneous investigation of multiple built environment characteristics (e.g., latent profiling) to garner a more complete understanding of neighborhood profiles that can promote or limit physical activity [31]. 


\section{Conclusion}

This research demonstrates that for the population of NSC, Auckland, New Zealand, coastal access and availability is related to residents accumulating health-promoting levels of physical activity. Maintaining and improving coastal access in neighborhoods where this is feasible may be worthwhile for promoting physical activity.

\section{Acknowledgements}

This work was supported by Sport New Zealand (previously Sport and Recreation New Zealand). The authors acknowledge the support of North Shore City Council, Harbour Sport, and Auckland University of Technology in providing in-kind staff support and access to GIS databases.

\section{References}

[1] Witten, K., Blakely, T., Bagheri, N., Badland, H., Ivory, V., Pearce, J., et al. (2012) Neighborhood Built Environment and Transport and Leisure Physical Activity: Findings Using Objective Exposure and Outcome Measures in New Zealand. Environmental Health Perspectives, 120, 971-977. https://doi.org/10.1289/ehp.1104584

[2] Giles-Corti, B., Bull, F., Knuiman, M., McCormack, G., Van Niel, K., Timperio, A., et al. (2013) The Influence of Urban Design on Neighbourhood Walking Following Residential Relocation: Longitudinal Results from the RESIDE Study. Social Science \& Medicine, 77, 20-30. https://doi.org/10.1016/j.socscimed.2012.10.016

[3] King, T.L., Thornton, L.E., Bentley, R.J. and Kavanagh, A.M. (2012) Does Parkland Influence Walking? The Relationship between Area of Parkland and Walking Trips in Melbourne, Australia. International Journal of Behavioral Nutrition and Physical Activity, 9, 115. https://doi.org/10.1186/1479-5868-9-115

[4] White, M.P., Alcock, I., Wheeler, B.W. and Depledge, M.H. (2013) Coastal Proximity, Health and Well-Being: Results from a Longitudinal Panel Survey. Health \& Place, 23, $97-$ 103. https://doi.org/10.1016/j.healthplace.2013.05.006

[5] Wheeler, B.W., White, M., Stahl-Timmins, W. and Depledge, M.H. (2012) Does Living by the Coast Improve Health and Wellbeing? Health \& Place, 18, 1198-201.

https://doi.org/10.1016/j.healthplace.2012.06.015

[6] Bauman, A.E., Smith, B., Stoker, L., Bellow, B. and Booth, M. (1999) Geographical Influences upon Physical Activity Participation: Evidence of a "Coastal Effect”. Australian and New Zealand Journal of Public Health, 23, 322-325. https://doi.org/10.1111/j.1467-842X.1999.tb01265.x

[7] Ball, K., Timperio, A., Salmon, J., Giles-Corti, B., Roberts, R. and Crawford, D. (2007) Personal, Social and Environmental Determinants of Educational Inequalities in Walking: A Multilevel Study. Journal of Epidemiology and Community Health, 61, 108-114. https://doi.org/10.1136/jech.2006.048520

[8] White, M.P., Wheeler, B.W., Herbert, S., Alcock, I. and Depledge, M.H. (2014) Coastal Proximity and Physical Activity: Is the Coast an Under-Appreciated Public Health Resource? Preventive Medicine, 69, 135-140. https://doi.org/10.1016/j.ypmed.2014.09.016

[9] Auchincloss, A.H., Gebreab, S.Y., Mair, C. and Diez Roux, A.V. (2012) A Review of Spatial Methods in Epidemiology, 2000-2010. Annual Review of Public Health, 33, 107-122. https://doi.org/10.1146/annurev-publhealth-031811-124655 
[10] Adams, M.A., Frank, L.D., Schipperijn, J., Smith, G., Chapman, J., Christiansen, L.B., et al. (2014) International Variation in Neighborhood Walkability, Transit, and Recreation Environments Using Geographic Information Systems: The IPEN Adult Study. International Journal of Health Geographics, 13, 43. https://doi.org/10.1186/1476-072X-13-43

[11] Ministry of Health (2004) Ethnicity Data Protocols for the Health and Disability Sector. Wellington.

[12] McLean, G. and Tobias, M. (2004) The New Zealand Physical Activity Questionnaires. Report on the Validation and Use of the NZPAQ-LF and NZPAQ-SF Self-Report Physical Activity Survey Instruments. Wellington.

[13] Haskell, W.L., Lee, I.M., Pate, R.R., Powell, K.E., Blair, S.N., Franklin, B.A., et al. (2007) Physical Activity and Public Health: Updated Recommendation for Adults from the American College of Sports Medicine and the American Heart Association. Medicine and Science in Sports and Exercise, 39, 1423-1434. https://doi.org/10.1249/mss.0b013e3180616b27

[14] Frank, L.D., Sallis, J.F., Saelens, B.E., Leary, L., Cain, K., Conway, T.L., et al. (2010) The Development of a Walkability Index: Application to the Neighborhood Quality of Life Study. British Journal of Sports Medicine, 44, 924-933. https://doi.org/10.1136/bjsm.2009.058701

[15] Von Elm, E., Altman, D.G., Egger, M., Pocock, S.J., Gotzsche, P.C., Vandenbroucke, J.P., et al. (2007) The Strengthening the Reporting of Observational Studies in Epidemiology (STROBE) Statement: Guidelines for Reporting Observational Studies. PLoS Medicine, 4, e296. https://doi.org/10.1136/bmj.39335.541782.ad

[16] Foster, C., Hillsdon, M., Jones, A., Grundy, C., Wilkinson, P., White, M., et al. (2009) Objective Measures of the Environment and Physical Activity-Results of the Environment and Physical Activity Study in English Adults. Journal of Physical Activity \& Health, 6, S70-S80. https://doi.org/10.1123/jpah.6.s1.s70

[17] Coombes, E., Jones, A.P. and Hillsdon, M. (2010) The Relationship of Physical Activity and Overweight to Objectively Measured Green Space Accessibility and Use. Social Science \& Medicine, 70, 816-822. https://doi.org/10.1016/j.socscimed.2009.11.020

[18] Pearce, J., Witten, K. and Bartie, P. (2006) Neighbourhoods and Health: A GIS Approach to Measuring Community Resource Accessibility. Journal of Epidemiology and Community Health, 60, 389-395. https://doi.org/10.1136/jech.2005.043281

[19] Boarnet, M.G., Greenwald, M. and McMillan, T.E. (2008) Walking, Urban Design, and Health: Toward a Cost-Benefit Analysis Framework. Journal of Planning Education and Research, 27, 341-358. https://doi.org/10.1177/0739456X07311073

[20] Chatman, D.G. (2009) Residential Choice, the Built Environment, and Nonwork Travel: Evidence Using New Data and Methods. Environment and Planning A, 41, 1072-1089. https://doi.org/10.1068/a4114

[21] McGinn, A.P., Evenson, K.R., Herring, A.H., Huston, S.L. and Rodriguez, D.A. (2007) Exploring Associations between Physical Activity and Perceived and Objective Measures of the Built Environment. Journal of Urban Health, 84, 162-184. https://doi.org/10.1007/s11524-006-9136-4

[22] De Bourdeaudhuij, I., Sallis, J.F. and Saelens, B.E. (2003) Environmental Correlates of Physical Activity in a Sample of Belgian Adults. American Journal of Health Promotion, 18, 83-92. https://doi.org/10.4278/0890-1171-18.1.83

[23] Forsyth, A., Oakes, J.M., Schmitz, K.H. and Hearst, M. (2007) Does Residential Density Increase Walking and Other Physical Activity? Urban Studies, 44, 679-697. https://doi.org/10.1080/00420980601184729

[24] Verran, D. (2010) The North Shore: An Illustrated History. Random House, Auckland. 
[25] Christian, H.E., Bull, F.C., Middleton, N.J., Knuiman, M.W., Divitini, M.L., Hooper, P., et al. (2011) How Important Is the Land Use Mix Measure in Understanding Walking Behaviour? Results from the RESIDE Study. International Journal of Behavioral Nutrition and Physical Activity, 8, 55. https://doi.org/10.1186/1479-5868-8-55

[26] Giles-Corti, B. and Donovan, R.J. (2002) The Relative Influence of Individual, Social and Physical Environment Determinants of Physical Activity. Social Science \& Medicine, 54, 1793-1812. https://doi.org/10.1016/S0277-9536(01)00150-2

[27] Tudor-Locke, C. and Myers, A. (2001) Challenges and Opportunities for Measuring Physical Activity in Sedentary Adults. Sports Medicine, 31, 91-100. https://doi.org/10.2165/00007256-200131020-00002

[28] Wilcox, S. and King, A.C. (2000) Self-Favoring Bias for Physical Activity in Middle-Aged Adults. Journal of Applied Social Psychology, 30, 1773-1789. https://doi.org/10.1111/j.1559-1816.2000.tb02467.x

[29] Mackay, L., Schofield, G. and Schluter, P.J. (2007) Validation of Self Report Measures of Physical Activity: A Case Study Using the New Zealand Physical Activity Questionnaire (NZPAQ). Research Quarterly for Exercise and Sport, 78, 189-196. https://doi.org/10.1080/02701367.2007.10599416

[30] Mackay, L.M., Oliver, M. and Schofield, G.M. (2011) Demographic Variations in Discrepancies between Objective and Subjective Measures of Physical Activity. Open Journal of Preventive Medicine, 2, 13-19. https://doi.org/10.4236/ojpm.2011.12003

[31] Adams, M.A., Sallis, J.F., Kerr, J., Conway, T.L., Saelens, B.E., Frank, L.D., et al. (2011) Neighborhood Environment Profiles Related to Physical Activity and Weight Status: A Latent Profile Analysis. Preventive Medicine, 52, 326-331.

https://doi.org/10.1016/j.ypmed.2011.02.020

Submit or recommend next manuscript to SCIRP and we will provide best service for you:

Accepting pre-submission inquiries through Email, Facebook, LinkedIn, Twitter, etc.

A wide selection of journals (inclusive of 9 subjects, more than 200 journals)

Providing 24-hour high-quality service

User-friendly online submission system

Fair and swift peer-review system

Efficient typesetting and proofreading procedure

Display of the result of downloads and visits, as well as the number of cited articles

Maximum dissemination of your research work

Submit your manuscript at: http://papersubmission.scirp.org/

Or contact ojpm@scirp.org 